\title{
Sleep, hypothalamus, and stigma
}

\author{
Peter Falkai · Hans-Jürgen Möller
}

Published online: 25 November 2010

(c) The Author(s) 2010. This article is published with open access at Springerlink.com

Dear colleagues,

The current issue of the European Archives of Psychiatry and Clinical Neurosciences covers some topics not being at the center of current psychiatric research but nevertheless stimulating and potentially interesting to the field.

In a representative German sample of 2,019 persons drawn from households, Schredl [1] investigated nightmare frequency and frequency of various nightmare topics. The five most common themes were falling, being chased, being paralyzed, being late, and the death of close persons. The author concludes that "even though several effects can be explained by the continuity hypothesis of dreaming, further research is needed to investigate the (possible metaphoric) relationship between nightmare topics and waking-life stressors".

Based on four well-described cases, Rossell et al. [2] develop a new cognitive model of delusions. All of these four cases had delusions as a consequence of post-traumatic brain injury without having a prior psychiatric illness. Overall, semantic processing was impaired in the four cases relative to a normative healthy control sample of 32 subjects. The cases performed better on tasks that required categorical identification, relative to the novel production of semantic information, which was poor in all four of the

P. Falkai $(\bowtie)$

Department of Psychiatry und Psychotherapy,

University of Göttingen, von-Siebold-Str. 5,

37075 Göttingen, Germany

e-mail: pfalkai@gwdg.de

H.-J. Möller

Psychiatry Hospital, Ludwig-Maximilians-University Munich,

Nussbaumstr. 7, 80336 München, Germany cases. These data are interpreted as preliminary evidence to support the notion of impaired semantic processing in persons with delusions.

The dysfunction of the hypothalamic-pituitary-adrenal axis is connected to the pathophysiology of affective syndromes. In the well done selective overview, Pompili et al. [3] suggest that the overactivity of the HPA axis may well predict the onset of mood disorders and perhaps even suicidal behavior via abnormalities in the serotonergic system.

A lot of attention is paid to the hypothalamus in affective disorders, while thalamic dysfunction and structural abnormalities are not a focus of research. In the study by Radenbach et al. [4], however, it was found that lithium treatment seems to have an impact on thalamic volumes in patients with bipolar disorder. Comparing patients with bipolar disorder and controls, no significant difference was found in this parameter, while subdividing the patient group into those treated with lithium compared to those without treatment revealed the above-mentioned difference. The study points to the importance of taking medication into account when researching biological parameters in major psychiatric disorders. Furthermore, it supports the notion of a neuroplastic effect of mood stabilizers and specifically lithium in psychiatric illnesses.

The prepulse inhibition (PPI) of the startle reflex is often used as a biological parameter allowing to bridge the gap between psychiatric diseases and their animal models [5]. The paper by Molina et al. [6] explored whether there is a difference between the PPI and neuropsychological deficits in chronic schizophrenia. This study suggests that PPI deficits in schizophrenia may not be contributing to cognitive deficits typical to this illness, although it has to be taken into account that the patients revealed a non-significant PPI decrease. 
Finally, we want to draw attention to an interesting paper by Rüsch et al. [7] exploring links between meritocratic worldviews and stigma. They measured just world believes for self and others as well as endorsement of the Protestant ethic in 85 people with schizophrenia, schizoaffective or affective disorder and in 50 members of the general public. Stigmatizing attitudes toward people with mental illness were assessed by self-report. The Protestant ethic may increase (self-)stigmatizing attitudes; just world believes for oneself, on the other hand, may lead to the unexpected implicit self-blame in stigmatized individuals. The authors conclude that public anti-stigma campaigns and initiatives to reduce self-stigma among people with mental illness should take worldviews into account. Furthermore, self-stigmatization might well be an overlooked finding however decreasing the willingness to seek psychiatric help [8].

Open Access This article is distributed under the terms of the Creative Commons Attribution Noncommercial License which permits any noncommercial use, distribution, and reproduction in any medium, provided the original author(s) and source are credited.

\section{References}

1. Schredl M (2010) Nightmare frequency and nightmare topics in a representative German sample. Eur Arch Psychiatry Clin Neurosci. doi:10.1007/s00406-010-0098-x
2. Rossell SL, Batty RA, Hughes L (2010) Impaired semantic memory in the formation and maintenance of delusions posttraumatic brain injury: a new cognitive model of delusions. Eur Arch Psychiatry Clin Neurosci. doi:10.1007/s00406-010-0101-6

3. Pompili M, Serafini G, Innamorati M, Möller-Leimkühler AM, Giupponi G, Girardi P, Tatarelli R, Lester D (2010) The hypothalamic-pituitary-adrenal axis and serotonin abnormalities: a selective overview for the implications of suicide prevention. Eur Arch Psychiatry Clin Neurosci. doi:10.1007/s00406-010-0108-Z

4. Radenbach K, Flaig V, Schneider-Axmann T, Usher J, Reith W, Falkai P, Gruber O, Scherk H (2010) Thalamic volumes in patients with bipolar disorder. Eur Arch Psychiatry Clin Neurosci. doi: 10.1007/s00406-010-0100-7

5. Maier W, Mössner R, Quednow BB, Wagner M, Hurlemann R (2008) From genes to psychoses and back: the role of the 5HT2alpha-receptor and prepulse inhibition in schizophrenia. Eur Arch Psychiatry Clin Neurosci 258(Suppl 5):40-43

6. Molina V, Cortés B, Pérez J, Martín C, Villa R, López DE, Sancho C (2010) No association between prepulse inhibition of the startle reflex and neuropsychological deficit in chronic schizophrenia. Eur Arch Psychiatry Clin Neurosci. doi:10.1007/s00406-010-0102-5

7. Rüsch N, Todd AR, Bodenhausen GV, Corrigan PW (2010) Do people with mental illness deserve what they get? Links between meritocratic worldviews and implicit versus explicit stigma. Eur Arch Psychiatry Clin Neurosci. doi:10.1007/s00406-010-0111-4

8. Schomerus G, Matschinger H, Angermeyer MC (2009) The stigma of psychiatric treatment and help-seeking intentions for depression. Eur Arch Psychiatry Clin Neurosci 259:298-306 